Research Article

\title{
Differences in the Values of the Senior Management Team, Antirisk Ability, and Innovation Performance by the Data-Driven Approach: Evidence from 841 Listed Companies in China
}

\author{
Guangyin Tong \\ School of Economics and Management, Zaozhuang University, Zaozhuang 277160, China \\ Correspondence should be addressed to Guangyin Tong; tong7892021@163.com
}

Received 20 September 2021; Revised 16 October 2021; Accepted 24 October 2021; Published 9 November 2021

Academic Editor: Ying Ji

Copyright (c) 2021 Guangyin Tong. This is an open access article distributed under the Creative Commons Attribution License, which permits unrestricted use, distribution, and reproduction in any medium, provided the original work is properly cited.

\begin{abstract}
This study explores the mechanism of corporate antirisk capabilities on corporate innovation performance by using a data-driven method. The data are from China's Shanghai and Shenzhen A-share listed companies from 2013 to 2018. The value differences between the senior management team's ability to resist risk and innovation performance are discussed. The results show that the antirisk ability of an enterprise will improve the efficiency of the utilization of enterprise resources and promote the formation of competitive advantage so that enterprises have a more stable internal and external environment, so as to improve the innovation performance of the enterprise. Risk capability improves corporate innovation performance; from the perspective of the value difference of the senior management team, a smaller value difference has a more significant effect on enhancing the enterprise's antirisk ability and improving corporate innovation performance than a larger value difference. While improving their own antirisk capabilities, companies should further promote and improve the consistency of senior management team values, thereby improving corporate innovation performance.
\end{abstract}

\section{Introduction}

Since the $19^{\text {th }}$ National Congress of the Communist Party of China, the Party Central Committee has formulated and issued a series of policies and measures to accelerate my country's economic transformation and upgrading [1]. In particular, on March 30, 2020, the Central Committee of the Communist Party of China and the State Council issued the "Opinions on Building a More Complete System and Mechanism for Factor Market Allocation," which clearly stated that the decisive role of the market in resource allocation should be fully utilized and the reform of factor market allocation should be deepened [2]. To promote the independent and orderly flow of factors, improve the efficiency of factor allocation, and further stimulate the creativity of the whole society and the vitality of the market, it is necessary to analyze the influent factors for enterprise innovation. Enterprise innovation performance is a comprehensive evaluation of the level of technological innovation of an enterprise [3], which embodies the effectiveness of the enterprise's innovation activities [4]. Examining and understanding the problems existing in the process of enterprise innovation and further mastering the relevant theories and methods of enterprise innovation performance evaluation will not only help the government to improve the enterprise innovation promotion policy but also help innovative enterprises conduct self-examination and selfcorrection and continue to improve [5].

Existing research believes that the main body of enterprise innovation is "entrepreneur," and the core function of entrepreneur is innovation [6]. Different entrepreneurs have different strategic choices for corporate innovation due to differences in knowledge, experience, abilities, values, and concepts [7]. Therefore, the consistency of values of the corporate senior management team is an important factor affecting corporate innovation performance. When a company is faced with major strategic innovation decisions, the more consistent values of the corporate senior 
management team, often determine the efficiency and direction of the innovation strategy selection, thereby affecting the company's development. The achievement of innovation performance has a significant impact [8]. In addition, under the common influence of many internal and external environments of the enterprise, through a series of decisionmaking behaviors of the enterprise's senior management team, the enterprise's risk-bearing ability is gradually formed and strengthened in the daily business activities of the enterprise [9]. On the one hand, the difference in values of corporate executive teams and their ability to resist risks are the two most basic internal and external factors that affect corporate operations [10]; on the other hand, when corporate ownership and management rights are separated, the conflict of interest shown by differences in the values of the corporate senior management team may lead to different business results in dealing with external market risks. The specific manifestation is the company's strong antirisk ability and insufficient antirisk ability [11]. The different antirisk abilities shown by companies will affect the company's innovation decision-making, thereby affecting the company's innovation performance [12]. According to the above literature, differences in the values of the senior management team have an important impact on the innovation behavior of the enterprise. The antirisk ability of the enterprise is the result of a series of decision-making behaviors of enterprise senior management, and the antirisk ability of the enterprise will eventually affect the innovation performance of the enterprise.

In recent years, with the continuous strengthening of the support of my country's corporate innovation policy, the impact of corporate executive team characteristics on corporate innovation has attracted great attention from the academic community [13-16]. These studies mainly take corporate innovation performance as the research object. On the basis of measuring the innovation performance of enterprises, the relationship between the educational background, professional background, demographic characteristics, and social capital of corporate executives and the relationship between corporate innovation performances have been actively discussed. However, the abovementioned research mainly focuses on the influence of external characteristic factors of the senior management team on corporate innovation behavior or performance, ignoring the role of internal characteristic factors such as values and behavioral cognition, and does not reveal deeply the differences in the values of the senior management team. The relationship and influence mechanism with enterprise innovation performance have been discussed.

At present, relevant research on the ability of senior management team to bear corporate risks has gradually emerged. Scholars have studied the impact of the characteristics of the senior management team on the corporate risk-taking ability $[17,18]$ and the characteristics of the senior management team and corporate innovation performance [19]. A lot of research studies have been carried out from different perspectives. It is particularly noteworthy that when enterprises take risks, they will have management effects. Managers are the direct decision-making subjects of enterprise investment behavior, which is significantly influenced by individual characteristics. Therefore, the heterogeneity of individual executives and the executive team will have a certain impact on an enterprise's ability to resist risks. However, there is still a lack of theoretical explanation and strict measurement test on how the difference in values of senior management team affects the enterprise's antirisk ability. Hao and Sun [20] have empirically examined the impact of the characteristics of senior management and their risk appetite on corporate innovation performance, but this research regards the characteristics of the senior management team and their risk appetite as a closely connected whole and does not consider the possible influence relationship between them. Scholars mainly use empirical methods to test the impact of enterprise antirisk ability on enterprise innovation performance. For example, Liu and Liang [21] proved that strong risk-bearing ability helps to achieve innovation performance and $\mathrm{Bi}$ and $\mathrm{Li}$ [22] proved that improving enterprise risk-taking ability in the market competition environment promotes enterprise innovation performance. These previous publications have laid a foundation for this article to carry out related research. However, how the value difference of top management team affects the risk resistance ability of the enterprise and the enterprise's innovation performance and what effect is still worthy of further study are questions. More importantly, the current research does not bring the differences between the values of the senior management team and the enterprise's ability to resist risks into a unified analysis framework to comprehensively examine its impact on enterprise innovation performance. Therefore, this paper is to reveal the coordination and performance of enterprise innovation more comprehensively.

In view of this, from the perspectives of the differences between the values of the senior management team and the enterprise's ability to resist risks, it analyzes the influencing factors behind the achievement of corporate technological innovation performance and explores the impact of the enterprise's antirisk ability on corporate innovation from two different dimensions: the smaller value difference and the higher value difference. The adjustment effect of the difference between performance mechanism and the senior management team will help us correctly understand the internal connection between the values of the corporate senior management team and innovation performance and provide certain theoretical reference and practical guidance for the improvement of corporate innovation performance.

The rest of this paper is organized as follows. Section 2 presents literature review and research hypothesis. Section 3 is the research and design. Section 4 proposes the empirical results and discussion. Section 5 concludes.

\section{Literature Review and Research Hypothesis}

\subsection{Enterprise's Antirisk Ability and Innovation Performance.} The theory of corporate behavior believes that organizational redundancy is the basic driving factor of corporate behavior, and it is necessary to incorporate it into the framework of the research on the relationship between corporate risk-taking 
and performance. When domestic and foreign scholars study the impact of corporate risk-taking ability on innovation performance, the representative view is that corporate risk-taking ability affects the efficiency of corporate capital allocation. John et al. [23] and Yu et al. [24] believe that risktaking means more choices of high-risk and high-return projects, indicating that managers can more fully identify and utilize investment opportunities and can significantly improve the capital allocation efficiency of the enterprise. Li et al. [25] believe that the venture capital department is an external Research and Development (hereinafter referred to as " $R \& D$ ") organization of a company, and performance is an important driving force for corporate venture capital. When the innovation performance of a company is close to social expectations, the company will not stop venture capital. The research of $\mathrm{Wu}$ and Yang [1] shows that when new companies need specialized complementary assets, compared with new companies that need general complementary assets, the funding of corporate venture capital will be more conducive to the performance of new companies. Zhang et al. [26] also pointed out that the participation of venture capital can reduce the uncertainty of technological innovation, increase the risk appetite of technology enterprises, and thus stimulate technological innovation performance. $\mathrm{Yu}$ et al. [27] found that there is a significant positive correlation between the level of risk-taking and corporate performance. Properly improving the risk-taking level of enterprise can promote the improvement of enterprise performance.

However, some scholars hold the opposite view. From the perspective of hidden costs of risk, we believe that it is the higher risk-taking of enterprises and the greater fluctuations in performance that lead to the conservative strategies of stakeholders and the decline in business performance. We believe that companies with good business performance are willing to take small risks, and they are unwilling to take risks to invest too much in $\mathrm{R} \& \mathrm{D}$ activities, and it is difficult for them to achieve significant improvement in innovation performance. There is a nonlinear relationship between corporate risk-taking and innovation performance. The level of enterprise risk-taking has a reasonable range and does not exceed the optimal level of risk-taking. Appropriately increasing enterprise risk-taking can promote enterprise innovation performance. $\mathrm{He}$ et al. [28] believe that entrepreneurs' overconfidence can promote corporate risktaking. This effect is limited to a modest range of corporate risk-taking. With the increase in entrepreneur's self-confidence, the enterprise's risk-taking is beyond reasonable scope. Not only does it fail to bring innovation performance to the enterprise, it may even lead to bankruptcy. Based on this, the following competitive research hypotheses are proposed.

Hypothesis 1a: assuming that other conditions remain unchanged, the more risk-resistant the enterprise is, the better the innovation performance

Hypothesis $1 \mathrm{~b}$ : assuming that other conditions remain the same, the stronger the enterprise's ability to resist risk, the worse the innovation performance
2.2. The Values of the Senior Management Team and the Company's Antirisk Ability. In the 1980s, the Upper Echelons Theory proposed by Hambrick and Mason believed that the economic and political environment of a manager's birth affects his or her values, cognitive risks, and behavioral decisions. For enterprises, the formulation and implementation process of strategic management is not an easy task. First, senior management personnel are required to have high professional quality and other qualities and abilities. The direction of strategic decision-making will also be affected by their entrepreneurs and senior executives and the influence of managers' cultural level and values [29]. At the same time, affected by the response of stakeholders as well as the corporate value and image perceived by the corporate executive team, the executive team will make strategic decisions based on their own experience, values, and personality characteristics, and the environment in which the company is located [30]. On the one hand, from the perspective of the personal characteristics of senior management team members, the background characteristics of corporate executives, including gender, age, education, service years, and professional experience have an impact on the decision-making behavior of senior management team and team organization process and affect the company's strategic choices and corporate performance [31]; on the other hand, from the perspective of the overall structural characteristics of the executive team, the composition of the corporate executive team generally consists of about ten people. There are inevitably differences in power and attitudes towards risk, and each has its own characteristics, which affects the decision-making process of the senior management team and the strategic choice of the company [32]. In fact, although the cognitive environment is the same, the cognitive abilities of corporate executives are affected by their cognitive willingness, knowledge, technology, information, and other factors, mainly including entrepreneurial attitudes, subjective norms (personal values and knowledge structure), and personal behavior. The difference in values composed of efficacy (personal background and risk meaning), etc., will lead to completely different decisions, behaviors and results [26]. As far as senior managers are concerned, they mainly make business decisions and strategic planning, which will be affected by their own perceptions, risk preferences, experience level, values, professionalism, innovation capabilities, etc. In addition to the impact of flexibility and communication skills, it is directly reflected in the company's ability to resist risks.

Studies have shown that the top managers in the senior management team tend to be different from other managers on the team due to factors such as their own educational background, length of service, and age, leading them to have opinions about cognitive structure, values, and risk awareness. Disagreement may also increase the interactive exchange of diversified information within the team, and this vertical difference will inevitably have an important impact on the company's innovative strategic decisionmaking, and different strategic choices will have an important impact on the company's ability to resist risks [33]. High-quality corporate executives and qualified employees 
should establish internal controls and risk values, which will help identify corporate strategy, operations, finance, legal, and other risk information and contribute to the occurrence of risk internal control imbalances within the company. At the same time, there are early warnings and strategies at the first time, so as to effectively enhance the enterprise's market risk-bearing capacity [34]. Ultimately, the psychological characteristics of managers, such as cognitive basis, values, and risk appetite, will affect the organization's strategic choices and company performance and then affect the company's ability to resist risks. Based on this, the following research hypotheses are proposed.

Hypothesis 2: assuming that other conditions remain the same, the greater the difference in the values of the senior management team is, the more helpful it is for the company to formulate innovation strategies and the stronger the company's ability to resist risks.

\subsection{Value Differences and Innovation Performance of the} Senior Management Team. Innovation is one of the most important tasks of the corporate executive team. Sun et al. [35] first proposed the theory of high-level echelon, which caused an in-depth study of the relationship between corporate executive team and innovation performance in academia. In the theory of technological innovation, technological innovation needs to be reflected through human behavior, and the senior management team, as the decision maker of corporate strategy, has an important influence on the strategic choices of corporate technology research and development and product innovation. Chen et al. [36] pointed out that although the senior management team is not directly involved in the company's technological innovation, as the highest headquarters of the company, the process of corporate strategic decision-making is inherently creative, and the innovation of the company's management mechanism also mainly comes from the senior management team, creative views, and ideas of members. Zhao et al. [37] showed that the senior management team of innovative enterprises and the management team members of the company's performance innovative enterprises have unique knowledge and skills, broad international vision, and strong learning ability. Only in this way can they have the awareness of innovation and guarantee and the ability to carry out innovation activities smoothly. Xiao et al. [38] proposed that the emergence of corporate innovation behavior is largely determined by the senior management team's awareness of innovative behavior. The stronger the senior management team's awareness of innovation is, the more innovation investment may be, thereby promoting the future of the company's growth and development. The differences in the values of corporate senior management teams have an important impact on strategic change, corporate performance, and whether to use corporate venture capital. In the existing research, scholars basically follow the "consistency assumption" of the values of the senior management team and replace cognition with easily observable demographic characteristics (such as gender, age, education level, professional background, and tenure). Subjective factors such as characteristics and values are used to predict the R\&D investment activities and innovation performance of the senior management team. $\mathrm{Yu}$ [39] pointed out that once the senior management team with high value consistency truly recognizes the value of the management innovation plan; they decide to implement the plan within the enterprise and personally participate in the plan to coordinate the deployment and allocation of resources. The implementation team led by the senior manager coordinates the work of various departments, reduces the resistance in the implementation process, organizes learning, trains employees, and forms a consistent understanding of the innovation plan, which can more effectively promote the implementation of the enterprise innovation plan, to better achieve "problem solving" and then to a greater extent to promote the improvement of enterprise innovation performance.

As the participants in the company's major decisionmaking and the director of daily work, the senior executives of the company are the core and soul of the company. Their decision-making behaviors and even their own quality directly affect the long-term development of the company, which is closely related to the company's performance and risk. Therefore, in the research of enterprise risk, it is often discussed from the perspective of the consistency of senior managers' values. Rong et al. [40] believe that Chinese people have always been influenced by Confucianism, the concept of the golden mean is deeply rooted, and the consistent value tendency makes risk aversion behaviors often appear, and executives hope to obtain long-term benefits from prudent investments. In [41], the fulfillment of corporate social responsibility focuses on the judgment standards of corporate executives' values. Corporate social responsibility can effectively improve the ability of the company to resist risks, attract outstanding employees, and increase the productivity of employees, thereby improving the company's performance and economic performance. Based on this, the following research hypotheses are proposed.

Hypothesis 3: assuming that other conditions remain unchanged, the consistency of the differences in the values of the senior management team will enhance the company's innovation performance by enhancing the ability to resist risks.

\section{Research and Design}

3.1. Data Source and Description. Select the 2013-2018 China Shanghai and Shenzhen A-share listed companies as the research object. The native place data of the main members of the senior management team are partly derived from the senior executive profile database of Guotai'an (CSMAR), but only about $30 \%$ of the listed company chairman and general manager's provincial (municipal) nationality data can be found in this database. We manually check the resumes and relevant news reports of the chairman and general manager through the Internet and manually supplement about $60 \%$ of the chairman and general manager's provincial (municipal) native place. If the hometown information of the chairman 
and general manager is missing, we will replace them with the province (city) where they were born.

The cultural dimension data of China's provinces (municipalities) come from the score data of cultural characteristics of all provinces (municipalities) across the country measured by the value measurement system based on the "Empirical Study on the impact of organizational identity on employee behavior effectiveness." reported by Wang et al. [42]. We use the cultural characteristics score of each province (city) across the country to measure the cultural scores of the provincial (city) where the chairman and general manager of listed companies are located to measure their personal values.

In order to ensure the validity of the sample, try to eliminate the influence of abnormal data on empirical research; data processing is mainly as follows: (1) exclude the data of the company's listing year and previous years; (2) exclude the data of financial companies; (3) exclude data abnormal data value and Winsor, processing the data. Finally, 5916 observation data were selected, and the related data processing and measurement analysis used stata14.0 software.

\subsection{The Explained Variable}

3.2.1. Innovation Performance. Existing documents mainly use the number of $\mathrm{R} \& \mathrm{D}$ personnel, $\mathrm{R} \& \mathrm{D}$ expenditure, the number of patents, and the number of registered trademarks as corporate innovation indicators [43, 44]. Among them, the number of $R \& D$ personnel and $R \& D$ expenditure indicators belong to the input indicators of enterprise innovation. Due to the long-term and risky nature of innovation input, such indicators cannot truly reflect the achievement of enterprise innovation performance, and the number of registered trademarks is used as an indicator of innovation output. The content of its reflection is quite different from that of the enterprise innovation performance studied in this article. Therefore, this article selects the cumulative number of patents (Inv) owned by a company as a measure of the size of the company's innovation performance.

\subsubsection{Explaining Variables}

(1) Differences in Values of the Senior Management Team (Detv). Based on the measurement based on the Globe cultural model reported by Liu et al. [45], this model contains a total of 9 dimensions: uncertainty avoidance, future orientation, power gap, sociallyoriented collectivism, small-group collectivism, interpersonal care orientation, performance orientation, gender equality, and dominance [46]. We use Euclidean distance to measure the difference between the chairman and general manager in these 9 cultural dimensions, and the calculation formula is as follows:

$$
\sqrt{\sum_{i=1}^{9}\left(V_{i 1}-V_{i 2}\right)^{2},}
$$

where $V_{i 1}$ represents the chairman's score on the GLOBE cultural model dimension 1 and $V_{i 2}$ represents the general manager's score on the GLOBE cultural model dimension 1. Assume a company with a chairman from Guangdong and a general manager from Heilongjiang. According to the cultural model of Zhao and Wei [47], Guangdong Province is in terms of uncertainty avoidance, future orientation, power gap, socially oriented collectivism, interpersonal care-oriented, performance-oriented, smallgroup collectivism, gender equality, and dominance 9. The scores of each dimension are 4.37, 4.37, 4.42, $4.72,4.51,4.66,5.05,3.61$, and 4.15 , while the scores of Heilongjiang Province in the corresponding 9 dimensions are $4.38,4.22,4.52,4.59,4.38,4.65,5.00$, 3.49 , and 4.01 , and the value difference between the two is $\sqrt{ }\left((4.37-4.38)^{2}+(4.37-4.22)^{2}+(4.42-4.52)\right.$ ${ }^{2}+(4.72-4.59)^{2}+(4.51-4.38)^{2}+(4.66-4.65){ }^{2}+(5.05-$ $\left.5.00)^{2}+(3.61-3.49)^{2}+(4.15-4.01)^{2}\right)=0.32$.

Finally, in order to further analyze the specific impact mechanism of different degrees of executive values on the corporate innovation performance, according to the results of relevant literature research, the difference in executive values is 1.500 as the boundary, and the differences in executive values are divided into low differences. Degree has a score value less than or equal to 1.500 , and high degree of difference has a score value greater than 1.500. Using this as a standard, in the total sample of $5916 \mathrm{ob}-$ servational data, there are 1626 data with low value differences and 4290 data with high value differences.

(2) Antirisk Ability (ART). Antirisk ability refers to the ability of enterprises and organizations to cope with crises. It can measure the health, capital, and industry status of an organization and enterprise. "Risk" is a very common term, which is often used around our lives. T.A. Kletz, a famous British industrial safety expert, pointed out human ignorance of risks at the $150^{\text {th }}$ anniversary meeting of the British Society for scientific development. With the continuous change of the environment, the connotation and extension of risk management have been greatly expanded, and the risk management activities have become increasingly rich. Risk management has become the focus of the management activities of many international large companies.

Because the study of enterprise risk tolerance is less and there are few measurement indicators that can be used for reference, this study refers to the research framework of the corporate risk-bearing level. Firstly, enterprise risk-taking behavior and its economic consequences are used as alternative variables of enterprise antirisk ability, specifically for the three different levels of indicators of the company's market share, operating gross profit margin, and cash ratio. Then, referring to the steps of principal component analysis comprehensive evaluation summarized by Lin and Sun [48]; the principal component analysis was performed on the above three corporate risk tolerance indicators, and the 
principal component comprehensive evaluation function was constructed and the sample value of the comprehensive function was calculated. Obtain the index value of the enterprise's antirisk ability.

3.2.3. Control Variables. In this paper, referring to previous studies (such as [49-51]), we controlled a series of variables at the enterprise level and corporate governance level. The enterprise level controls the enterprise size (Ens), asset-liability ratio (Fle), and enterprise performance (ROA). At the corporate governance level, we control the size of the board of directors (Bsi) and board independence (Bin).

3.3. Model Construction and Variable Definition. The following basic model is constructed to analyze the impact of corporate antirisk capabilities on innovation performance:

$$
\operatorname{Inv}_{i, t}=\beta_{0}+\beta_{1} \mathrm{ART}_{i, t}+\text { Controls }_{i, t}+\sum \text { year }+\sum \text { Ind }+\varepsilon_{i, t} \text {. }
$$

Model (2) takes $\operatorname{Inv}_{i, t}$ as the dependent variable, $\mathrm{ART}_{i, t}$ as the main explanatory variables, and particularly selects the enterprise scale (Ens), asset-liability ratio (Fle), and enterprise performance (ROA) as the control variables from the enterprise management level to explore the enterprise. The impact of antirisk ability on enterprise innovation performance is determined. Enterprise size (Ens) is an important indicator to evaluate the business ability of an enterprise, reflecting whether the enterprise has the basis for future development. The larger the size of the enterprise, the better the innovation performance of the enterprise. The debt-toasset ratio (Fls) is an important indicator to evaluate the solvency of a company, and it can reflect the size of the company's financing ability. Only by keeping the debt-toasset ratio at a reasonable level can companies improve the likelihood of achieving innovative performance. Among them, the return on total assets (ROA) is an important indicator to evaluate the profitability of a company. The higher the return on total assets, the more likely it is that the company's innovation performance will improve. In model (2), it is expected that $\beta 1>0$, that is, the enterprise's antirisk ability will increase the possibility of achieving innovation performance.

In order to verify the impact of differences in senior management values on the enterprise's ability to resist risks, a model (3) is constructed:

$$
\mathrm{ART}_{i, t}=\beta_{0}+\beta_{1} \operatorname{Detv}_{i, t}+\text { Controls }_{i, t}+\sum \text { year }+\sum \text { Ind }+\varepsilon_{i, t} .
$$

Model (3) uses $\mathrm{ART}_{i, t}$ as dependent variables and $\operatorname{Detv}_{i, t}$ as the main explanatory variables. Especially, from the governance level of listed companies, the enterprise scale (Ens) and asset-liability ratio (Fle) are selected as control variables from the corporate management level to explore the impact of differences in senior management values on corporate antirisk capabilities. Enterprise size (Ens) is an important indicator to evaluate the business ability of an enterprise, reflecting whether the enterprise has the basis for future development. The larger the company, the stronger the ability to resist risks. The debt-to-asset ratio (Fls) is an important indicator for evaluating the solvency of a company, and it can reflect the size of the company's financing ability. Only when the company's debt-to-asset ratio remains at a reasonable level is the company more likely to withstand risk. In model (3), it is expected that $\beta 1<0$, that is, differences in corporate executive values will reduce the company's ability to resist risks.

In order to verify the impact of differences in senior management values on corporate innovation performance, model (4) is constructed:

$$
\operatorname{Inv}_{i, t}=\beta_{0}+\beta_{1} \operatorname{Detv}_{i, t}+\text { Controls }_{i, t}+\sum \text { year }+\sum \operatorname{Ind}+\varepsilon_{i, t} .
$$

Model (4) uses $\operatorname{Inv}_{i, t}$ as the dependent variable and Detv ${ }_{i}$ ${ }_{t}$ as the main explanatory variable. Especially, from the level of listed company governance, it selects the board size (Bsi) and board independence (Bin) as the control variables to explore executives. The impact of differences in values on corporate innovation performance is determined. The size of the board of directors (Bsi) is an important indicator to evaluate the management level of an enterprise, reflecting the level of the establishment of a modern enterprise shareholding system. The larger the board of directors is, the more the company will focus on its long-term development and the better its innovation performance is. The independence of the board of directors (Bin) is an important indicator for evaluating the scientificity and rationality of corporate internal governance. It can reflect the level of decision-making ability of the company. Only by setting up the position of independent director scientifically can the company make relevant major decisions to ensure its scientificity and rationality. Therefore, companies are more likely to achieve higher innovation performance. In model (4), it is expected that $\beta 1>0$, that is, differences in corporate executive values will increase the possibility of achieving innovation performance.

In order to further verify the moderating effect of the differences in corporate executive values and their different degrees of differences on the relationship between corporate antirisk capabilities and innovation performance, model (5) is set up:

$$
\begin{aligned}
\operatorname{Inv}_{i, t}= & \beta_{0}+\beta_{1} \operatorname{Detv}_{i, t}+\beta_{2} \operatorname{Detv}_{i, t} \times \mathrm{ART}_{i, t}+\beta_{3} \mathrm{ART}_{i, t} \\
& + \text { Controls }_{i, t}+\sum \text { year }+\sum \text { Ind }+\varepsilon_{i, t} .
\end{aligned}
$$

Model (5) introduces the interaction terms between the differences in values of senior management and the ability to resist risks to study whether the differences in values of senior management can further enhance the impact of the ability to resist risks on enterprise innovation performance. In model (5), it is expected that $\beta 2>0$, that is, differences in 
the values of senior management can improve the possibility of enterprise innovation performance by enhancing the enterprise's antirisk ability.

The settings and definitions of variables in each model are shown in Table 1:

\section{Empirical Results and Analysis}

4.1. Descriptive Statistics. The descriptive statistical results of each variable are shown in Table 2. There are 5916 observations in total. Among them, 1626 had observational data with a low degree of difference in executive values, accounting for $27.48 \% ; 4,290$ had observational data with a high degree of difference in executive values, accounting for $72.52 \%$. The proportion of executives in Shanghai and Shenzhen A-share listed companies with high value difference is much higher than that in companies with low value difference, indicating that the geographical and cultural characteristics of executives in China's Shanghai and Shenzhen A-share listed companies are indicative. The phenomenon of large differences in values is even more obvious. The standard error of the cumulative number of patents owned by the entire sample of companies is 33.664 , and the minimum and maximum values are 0 and 455 , respectively, indicating that there is a large degree of difference in the achievement of corporate innovation performance. Even listed companies also have the number of patents. The average value difference score of the senior management team of the full sample is 2.42 , indicating that the difference in values of the senior management team of China's Shanghai and Shenzhen A-share listed companies is relatively large; the standard error of the difference in the values of the senior management team is 1.259 , indicating the internal values of the senior management team of the listed company. There are obvious differences. The minimum and maximum antirisk capabilities of the full-sample companies are 0.0147 and 0.0522 , respectively, and the average and standard errors are 0.0337 and 0.0120 , respectively, indicating that the overall performance of China's Shanghai and Shenzhen A-share listed companies' antirisk capabilities is relatively weak, and the difference is not the same, big. The minimum and maximum sizes of the full sample companies are 2.7665 and 4.6052 , respectively, and the average and standard errors are 3.9989 and 0.3814 , respectively, indicating that the scale of China's Shanghai and Shenzhen A-share listed companies has maintained a certain level, and the difference is not obvious. The average asset load ratio of the entire sample is 0.4613 , indicating that the overall debt level of China's Shanghai and Shenzhen A-share listed companies is relatively large. The average return on total assets of the full sample is $1.99 \%$, indicating the overall profitability of A-share listed companies in Shanghai and Shenzhen, China; the standard error of the return on total assets is $3.27 \%$, indicating that there is a significant difference in the profitability of listed companies. The minimum and maximum board sizes of the full sample are 1.693 and 13.526, and the average and standard errors are 2.355 and 8.345 , respectively, indicating that the size of the board of directors of China's Shanghai and Shenzhen A-share listed companies has maintained a certain level and the difference is obvious. From the perspective of the proportion of independent directors, the average value is $36.78 \%$, the standard error is $9.84 \%$, the structure is more reasonable, the independence is good, and the difference between samples is not obvious.

4.2. Correlation Analysis. Correlation analysis of the main variables (Table 3 ) lists the Pearson correlation test results. It can be seen from Table 3 that the Pearson coefficient of enterprise antirisk ability and enterprise innovation performance is 0.025 , and there is a significant positive correlation at the $1 \%$ statistical level, indicating that there is a correlation between enterprise antirisk ability and innovation performance; enterprise antirisk ability, innovation performance, and differences in the values of the senior management team are all significantly related, indicating that there is a certain connection between the differences in the values of the senior management team and the enterprise's ability to resist risks, and there is a certain connection between the two and the achievement of enterprise innovation performance. Except for individual control variables, the correlation coefficients of other control variables are all less than 0.6 , so there is no co-linearity problem in regression analysis.

4.3. Antirisk Ability and Innovation Performance. Two models of OLS estimation and fixed effects are used to test the relationship between the enterprise's antirisk ability and innovation performance. The regression results are shown in Table 4. From the full-sample regression results, it can be seen that the coefficient of inefficient investment under the OLS estimation method is 0.027 , and the coefficient of inefficient investment under the fixed effects model is 0.023 , both of which are greater than 0 , indicating that the firm's ability to resist risks is positively correlated with innovation performance. That is, the enhancement of the enterprise's antirisk ability will directly improve the enterprise's innovation performance so that hypothesis $1 \mathrm{a}$ is verified and hypothesis $1 \mathrm{~b}$ should be discarded.

The difference in values of senior management team of an enterprise can be divided into two situations: low difference and high difference. Is there any difference in the positive impact of enterprise's antirisk ability on the innovation performance of the two forms? To this end, two subsamples with low and high degrees of difference were regression tested. It can be seen from Table 4 that the coefficients of the antirisk ability of the low degree of difference subsample under the OLS estimation and the fixed-effect model are 0.005 and 0.018 , respectively, and the coefficients of the high degree of difference subsample have the antirisk ability under the OLS estimation and the fixed effect model, respectively, are 0.035 and 0.038 . Through comparison, it can be found that whether it is an OLS estimation or a fixedeffect model, the coefficient of the antirisk ability of the subsamples with a high degree of difference is much larger than the coefficient of the antirisk ability of the subsamples with a low degree of difference. The greater the difference in 
TAвLE 1: Variable settings and definitions.

\begin{tabular}{|c|c|c|c|}
\hline Variable type & Variable name & $\begin{array}{l}\text { Variable } \\
\text { symbol }\end{array}$ & Variable description \\
\hline Explained variable & Number of patents & Inv & Number of invention patents owned by the company \\
\hline \multirow[t]{2}{*}{ Explanatory variables } & $\begin{array}{l}\text { Differences in the values of the } \\
\text { senior management team }\end{array}$ & Detv & $\begin{array}{l}\text { Based on the "empirical study on the impact of organizational } \\
\text { identity on employee behavior effectiveness." reported by Wang } \\
\text { et al. [ } 42] \text {; the Euclidean distance is then used to measure the } \\
\text { difference between the chairman and the general manager in } \\
\text { these } 9 \text { cultural dimensions }\end{array}$ \\
\hline & Antirisk ability* & ART & $\begin{array}{l}\text { The comprehensive function value obtained after the principal } \\
\text { component analysis of the enterprise risk-bearing ability index }\end{array}$ \\
\hline \multirow{3}{*}{$\begin{array}{l}\text { Control variable } \\
\text { (enterprise level) }\end{array}$} & Enterprise size & Ens & The natural logarithm of the company's total assets \\
\hline & Assets and liabilities & Fle & $\begin{array}{c}\text { Total liabilities at the end of the year/total assets at the end of the } \\
\text { year }\end{array}$ \\
\hline & Business performance & ROA & $\begin{array}{c}\text { Total profit at the end of the year/(total assets at the end of the } \\
\text { year + total assets at the beginning of the year) }\end{array}$ \\
\hline \multirow{2}{*}{$\begin{array}{l}\text { Control variable } \\
\text { (corporate governance } \\
\text { level) }\end{array}$} & Board size & Bsi & \multirow{2}{*}{$\begin{array}{c}\text { The total number of board members takes the natural logarithm } \\
\text { Number of independent directors/total number of board of } \\
\text { directors }\end{array}$} \\
\hline & Board independence & Bin & \\
\hline \multirow[b]{2}{*}{ Control variable (others) } & Year & Year & \multirow{2}{*}{$\begin{array}{c}\text { Annual dummy variable } \\
\text { Industry dummy variables defined based on the industry } \\
\text { classification of the China securities regulatory commission }\end{array}$} \\
\hline & Industry & Ind & \\
\hline
\end{tabular}

*, in Model (3), is the explained variable.

TABLE 2: Descriptive statistical results of main variables.

\begin{tabular}{|c|c|c|c|c|c|}
\hline Variables & $\mathrm{N}$ & Minimum & Maximum & Mean & Standard deviation \\
\hline Inv & 5916 & .0000 & 455.0000 & 24.6357 & 33.6641 \\
\hline Detv & 5916 & .0000 & 4.0800 & 2.4202 & 1.2592 \\
\hline ART & 5916 & .0147 & .0522 & .0337 & .0120 \\
\hline Ens & 5916 & 2.7665 & 4.6052 & 3.9989 & .3814 \\
\hline Fle & 5916 & .0108 & 0.8477 & .4613 & .2118 \\
\hline $\mathrm{ROA}$ & 5916 & -7.2530 & 26.5761 & 1.9913 & 3.2738 \\
\hline Bsi & 5916 & 1.6931 & 13.5264 & 2.3551 & 8.3447 \\
\hline Bin & 5916 & .0667 & .8333 & .3678 & .0984 \\
\hline
\end{tabular}

TABle 3: Pearson correlation analysis.

\begin{tabular}{lccccccc}
\hline & Inv & Detv & ART & Ens & Fle & ROA & Bsi \\
\hline Inv & 1 & & & & & & \\
Detv & $.039^{* *}$ & 1 & & & & \\
ART & $.025^{* *}$ & $.046^{* *}$ & 1 & & & \\
Ens & $.030^{*}$ & $.055^{* *}$ & $.042^{* *}$ & 1 & & \\
Fle & -.023 & $-.068^{* *}$ & $-.057^{* *}$ & $-.035^{* *}$ & 1 & & \\
ROA & .021 & $.058^{* *}$ & $.041^{* *}$ & $.173^{* *}$ & $-.093^{* *}$ & 1 & \\
Bsi & -.007 & .021 & -.003 & .006 & -.011 & .012 & 1 \\
Bin & .003 & .023 & .018 & .003 & -.012 & .006 & $-.331^{* *}$ \\
\hline
\end{tabular}

**, significantly correlated at the 0.01 level (two-sided); ${ }^{*}$, significantly correlated at the 0.05 level (two-sided).

management values is, the more a company's ability to resist risks can promote its innovation performance.

As shown in Table 4, the regression coefficient between antirisk ability and innovation performance under different degree has obvious difference. This is because when enterprises have strong antirisk ability, they will continue to increase the investment in $\mathrm{R} \& \mathrm{D}$ expenses, and more research literature shows that a higher level of $R \& D$ investment will lead to an increase in enterprise innovation performance.
4.4. Differences in Values of the Senior Management Team and Antirisk Ability. Two models of OLS estimation and fixed effects are used to test the relationship between the differences in the values of the senior management team and the enterprise's ability to resist risks. The regression results are shown in Table 5. From the full-sample regression results, it can be seen that the coefficient of the difference in the values of the executive team under the OLS estimation method is -0.039 , and the coefficient of the difference in the values of the executive team under the fixed effects model is -0.051 , 
TABLE 4: Regression analysis results of antirisk ability and innovation performance.

\begin{tabular}{|c|c|c|c|c|c|c|}
\hline \multirow{2}{*}{ Variable name } & \multicolumn{2}{|c|}{ Full sample } & \multicolumn{2}{|c|}{ Low degree of difference } & \multicolumn{2}{|c|}{ High degree of difference } \\
\hline & $(1)$ & (2) & (3) & $(4)$ & (5) & (6) \\
\hline Antirisk ability & $.027^{* *}$ & $.023^{* *}$ & $.005^{*}$ & $.018^{*}$ & $.035^{* *}$ & $.038^{* * *}$ \\
\hline Enterprise size & $-.043^{*}$ & $.026^{* *}$ & .001 & .022 & $-.021^{* *}$ & $.026^{* *}$ \\
\hline Assets and liabilities & -.010 & $-.019^{*}$ & $-.007^{*}$ & .008 & .003 & $-.026^{* *}$ \\
\hline Business performance & $-.074^{*}$ & $.014^{*}$ & -.030 & $.022^{*}$ & $-.013^{*}$ & .010 \\
\hline Board size & .021 & -.009 & .017 & $-.006^{* *}$ & -.002 & $-.011^{*}$ \\
\hline Board independence & .056 & $-.004^{*}$ & $-.011^{*}$ & .036 & .008 & -.017 \\
\hline Year fixed & $\mathrm{NO}$ & YES & NO & YES & NO & YES \\
\hline Industry fixed & $\mathrm{NO}$ & YES & $\mathrm{NO}$ & YES & $\mathrm{NO}$ & YES \\
\hline$N$ & 5916 & 5916 & 1626 & 1626 & 4290 & 4290 \\
\hline$R^{2}$ & 0.0360 & 0.0460 & 0.0312 & 0.0458 & 0.0390 & 0.0452 \\
\hline
\end{tabular}

TABLE 5: Regression analysis results of differences in the values of the senior management team and the ability to resist risks.

\begin{tabular}{|c|c|c|c|c|c|c|}
\hline \multirow[t]{2}{*}{ Variable name } & \multicolumn{2}{|c|}{ Full sample } & \multicolumn{2}{|c|}{$\begin{array}{l}\text { Low degree of } \\
\text { difference }\end{array}$} & \multicolumn{2}{|c|}{$\begin{array}{l}\text { High degree of } \\
\text { difference }\end{array}$} \\
\hline & $(1)$ & $(2)$ & (3) & $(4)$ & $(5)$ & (6) \\
\hline Differences in the values of the senior management team & $-.039^{* * *}$ & $-.051^{* * *}$ & $.033^{*}$ & -.051 & .008 & $-.011^{* *}$ \\
\hline Enterprise size & .033 & $.047^{* *}$ & .012 & $.022^{*}$ & $.042^{* * *}$ & $.058^{* *}$ \\
\hline Assets and liabilities & $-.051^{* * *}$ & -.034 & $-.058^{*}$ & -.041 & $-.047^{* * *}$ & $-.039^{*}$ \\
\hline Business performance & $.028^{*}$ & $.033^{* *}$ & $.044^{*}$ & $.053^{* *}$ & .022 & .031 \\
\hline Year fixed & NO & YES & NO & YES & $\mathrm{NO}$ & YES \\
\hline Industry fixed & $\mathrm{NO}$ & YES & $\mathrm{NO}$ & YES & NO & YES \\
\hline$N$ & 5916 & 5916 & 1626 & 1626 & 4290 & 4290 \\
\hline$R^{2}$ & 0.0670 & 0.0850 & 0.0334 & 0.0471 & 0.0290 & 0.0352 \\
\hline
\end{tabular}

both of which are less than 0 , indicating the values of the executive team. The difference is negatively related to the enterprise's antirisk ability, that is, the increase of the difference in the values of the senior management team will reduce the enterprise's antirisk ability, thus verifying Hypothesis 2 .

The difference in the values of the senior management team is divided into two situations: low difference and high difference. The level of difference in the values of the senior management team has a greater impact on the enterprise's antirisk ability or the difference between the two levels of executive value. Are there differences in the negative impact of corporate innovation performance? It can be seen from Table 5 that the coefficients of the differences in the values of the executive team under the OLS estimation and the fixedeffect model for the low degree of difference subsample are 0.033 and -0.051 , respectively. The coefficients of the difference in values are -0.008 and -0.011 , respectively. Through comparison, it can be found that whether it is an OLS estimation or a fixed-effect model, the absolute value of the coefficient of the difference in values of the senior management team of the subsample with a high degree of difference is much smaller than the absolute value of the coefficient of the difference in values of the executive team of the subsample with a low degree of difference, which indicates that the smaller the difference in team values is, the more consistent the difference in values of the corporate executive team and the better the ability of enterprises to resist risks.
4.5. Differences in Values of Senior Management Teams and Innovation Performance. Two models of OLS estimation and fixed effects are used to test the relationship between the differences in the values of senior management team and the innovation performance of the enterprise. The regression results are shown in Table 6. From the full-sample regression results, it can be seen that the coefficient of the difference in the values of the executive team under the OLS estimation method is -0.040 , and the coefficient of the difference in the values of the executive team under the fixed effects model is -0.036 , both of which are less than 0 , indicating the values of the executive team. Differences are negatively related to corporate innovation performance, that is, increasing differences in the values of the senior management team will reduce corporate innovation performance, thus enabling Hypothesis 3 to be verified.

The difference in values of senior management team can be divided into two situations: low difference and high difference. To what extent do the differences in the values of the senior management team have an impact on the innovation performance of the enterprise or to what extent do the differences in the values of the two-level senior management have an impact on the innovation performance of the enterprise? Is there a difference in the positive impact? It can be seen from Table 6 that the coefficients of the differences in the values of the executive team under the OLS estimation and the fixed-effect model for the low-level difference subsample are -0.022 and 0.063 , respectively. The coefficients of the difference in values are 0.010 and -0.043 , 
TABLE 6: Regression analysis results of differences in the values of the senior management team and innovation performance.

\begin{tabular}{|c|c|c|c|c|c|c|}
\hline \multirow[t]{2}{*}{ Variable name } & \multicolumn{2}{|c|}{ Full sample } & \multicolumn{2}{|c|}{$\begin{array}{l}\text { Low degree of } \\
\text { difference }\end{array}$} & \multicolumn{2}{|c|}{$\begin{array}{l}\text { High degree of } \\
\text { difference }\end{array}$} \\
\hline & (1) & $(2)$ & (3) & $(4)$ & $(5)$ & $(6)$ \\
\hline Differences in the values of the senior management team & $-.040^{* * *}$ & $-.036^{* * *}$ & $-.022^{* *}$ & .063 & .010 & $-.043^{* *}$ \\
\hline Enterprise size & -.013 & $.025^{* *}$ & .001 & $.021^{*}$ & $-.019^{*}$ & $.027^{* * *}$ \\
\hline Assets and liabilities & .000 & $-.018^{*}$ & -.007 & .009 & .002 & $-.027^{* * *}$ \\
\hline Business performance & $-.018^{* *}$ & .013 & $-.032^{*}$ & $.021^{*}$ & $-.012^{*}$ & .010 \\
\hline Board size & .004 & -.010 & .015 & -.006 & -.001 & -.011 \\
\hline Board independence & .003 & $-.005^{*}$ & -.011 & $.035^{* *}$ & .009 & $-.017^{* *}$ \\
\hline Year fixed & NO & YES & NO & YES & $\mathrm{NO}$ & YES \\
\hline Industry fixed & $\mathrm{NO}$ & YES & $\mathrm{NO}$ & YES & NO & YES \\
\hline$N$ & 5916 & 5916 & 1626 & 1626 & 4290 & 4290 \\
\hline$R^{2}$ & 0.0260 & 0.0382 & 0.0300 & 0.0408 & 0.0363 & 0.0478 \\
\hline
\end{tabular}

respectively. Through comparison, it can be found that whether it is an OLS estimation or a fixed-effect model, the absolute value of the coefficient of the difference in values of the senior management team of the subsample with a high degree of difference is much smaller than the absolute value of the coefficient of the difference in values of the executive team of the subsample with a low degree of difference, which indicates the executives. The smaller the difference in team values, the more consistent the differences in the values of the corporate executive team and the better the innovation performance of the enterprise.

4.6. Tests on the Moderating Effect of Differences in Senior Management Values. Two models of OLS estimation and fixed effects are used to test the moderating effect of the differences in the values of the senior management team against risk and innovation performance. The regression results are shown in Table 7 . From the regression results of the full sample, it can be seen that the coefficients of the company's antirisk ability under the OLS estimation and the fixed effects model are 0.002 and 0.005 , respectively, which are both greater than 0 , indicating that the enhancement of the company's antirisk ability will improve the company's innovation performance; the coefficients of the interaction term between value difference and antirisk ability under OLS estimation and fixed-effect model are 0.052 and 0.049 , respectively, which are both greater than 0 , indicating that the difference in values of the senior management team can enhance the enterprise's antirisk ability, thereby improving the innovation performance of the enterprise.

Is there any difference in the moderating effect of the difference in values between the top management team and the bottom management team on the enterprise's ability to resist risks? It can be seen from Table 7 that the coefficients of the interaction term between the corporate antirisk ability and the differences in the values of the senior management team under the OLS estimation and the fixed effect model of the low degree of difference subsample are 0.118 and 0.104 , respectively, and the high degree of difference subsample is estimated and fixed in the OLS. Under the effect model, the coefficients of the interaction terms between the corporate antirisk ability and the difference in the values of the senior management team are 0.120 and 0.146 , respectively, which are both greater than 0 , indicating that the difference in the values of the senior management team can play an effective moderating effect regardless of whether it is a low or a high degree of difference to enhance the innovation performance of the enterprise. At the same time, through comparison, it can be found that whether it is OLS estimation or fixed-effect model, the value of the interaction term coefficient of corporate antirisk ability and the value difference of the senior management team under the high degree of difference subsample is smaller than that of the low degree of difference subsample, indicating the difference in management team values has a greater moderating effect on the enterprise's ability to resist risks.

4.7. Robustness Test. In order to obtain a more robust regression result, the research model was further used as a substitute variable for corporate innovation performance to conduct regression analysis on corporate $\mathrm{R} \& \mathrm{D}$ expenditure. The test results showed that the coefficients of antirisk ability were all positive and reached a statistically significant level; the interaction terms between the corporate antirisk ability and the differences in the values of the senior management team are both positive and reach a statistically significant level; this is consistent with the previous results so that the conclusions of this article are supported to a certain extent. In addition, considering that the problems of innovation and transformation of China's Shanghai and Shenzhen A-share manufacturing industries from 2011 to 2016 are more prominent, and the selected sample size is relatively large; manufacturing data are selected for robustness testing. In order to alleviate the endogenous problems caused by sample selection bias and the two-way influence of variables, the industry average of enterprise antirisk ability is taken as the instrumental variable of enterprises' antirisk ability. The conclusion is further supported (limited to space, the specific process and results of robustness test will not be reported).

The success of any business depends on the senior management team. Team members have to work together, and sometimes there are differences of team members' opinions. We can understand the issue of differences in the values of the senior management team from two perspectives [52]. One perspective is that executives have different backgrounds and values, which can make corporate 
TABLE 7: Tests on the moderating effects of the differences in senior Management's values against risks and innovation performance.

\begin{tabular}{|c|c|c|c|c|c|c|}
\hline \multirow[t]{2}{*}{ Variable name } & \multicolumn{2}{|c|}{ Full sample } & \multicolumn{2}{|c|}{$\begin{array}{l}\text { Low degree of } \\
\text { difference }\end{array}$} & \multicolumn{2}{|c|}{$\begin{array}{l}\text { High degree of } \\
\text { difference }\end{array}$} \\
\hline & $(1)$ & $(2)$ & $(3)$ & $(4)$ & $(5)$ & $(6)$ \\
\hline Antirisk ability & $.002^{*}$ & $.005^{*}$ & .055 & $.026^{* *}$ & -.065 & $.072^{* *}$ \\
\hline Antirisk ability $\times$ differences in values of the senior management team & $.052^{* *}$ & $.049^{* * *}$ & $.120^{* * *}$ & $.146^{*}$ & $.118^{*}$ & $.104^{* *}$ \\
\hline Differences in the values of the senior management team & $.001^{*}$ & $.003^{*}$ & $.144^{* *}$ & $.098^{* *}$ & $-.058^{* *}$ & $.044^{* *}$ \\
\hline Enterprise size & $-.014^{* *}$ & $.024^{* * *}$ & .001 & $.023^{*}$ & $-.021^{* *}$ & $.026^{* * *}$ \\
\hline Assets and liabilities & .001 & $-.017^{* *}$ & -.006 & .009 & .004 & $-.025^{*}$ \\
\hline Business performance & $-.019^{* * *}$ & $.013^{*}$ & $-.032^{* *}$ & $.022^{*}$ & -.013 & .010 \\
\hline Board size & $.004^{*}$ & -.010 & .015 & -.007 & $-.002^{*}$ & -.012 \\
\hline Board independence & .002 & -.005 & -.011 & $.035^{* *}$ & .008 & $-.017^{*}$ \\
\hline Year fixed & $\mathrm{NO}$ & YES & NO & YES & NO & YES \\
\hline Industry fixed & $\mathrm{NO}$ & YES & $\mathrm{NO}$ & YES & NO & YES \\
\hline$N$ & 5916 & 5916 & 1626 & 1626 & 4290 & 4290 \\
\hline$R^{2}$ & 0.0300 & 0.0410 & 0.0331 & 0.0460 & 0.0390 & 0.0501 \\
\hline
\end{tabular}

decisions more scientific and effective. Another perspective is that differences within the executive team can also be beneficial. This is mainly because differences can enhance creativity, which can improve the team's decision-making level. More important, when there are differences in values in the senior management team, relationship conflicts are more likely to bring more negative effects. One explanation is that differences in values make senior management team members sensitive to differences. When members of the executive team find that their values are inconsistent, they will drift away. Therefore, when the senior management team lacks consensus and sense of belonging, the company's working atmosphere and spirit of collaboration will be damaged.

One of the worst examples is Enron. They listed the company's core values in the mission statement: respect, integrity, communication, and excellence. When Enron's late former CEO, Kenneth Lay, conducted a survey of Enron's executives and asked them "what is the company's core values;" they thought "what does he value as a CEO." Not only that, Neilman did not accuse the two employees of leaking flight records, but took responsibility for their mistakes because "management obviously did not guide them correctly." Some task conflicts can lead to constructive arguments, but relationship conflicts can hinder effective decision-making [53]. Therefore, the company should minimize the relationship conflicts within the senior management team, while encouraging the ultimate improvement of decision-making behavior and company operations.

\section{Conclusions}

This article uses my country's 2013-2018 Shanghai and Shenzhen listed companies as a sample. Based on the measurement data of cultural value system of various provinces (municipalities) across the country and the hometown data of chairman and general manager, this article measures the difference of their values and makes an empirical analysis on the values of senior executives. Differences and enterprise antirisk ability have an impact on enterprise innovation performance and further test the role of differences in executive values. The empirical results show that the following. (1) The enterprise's antirisk ability is positively correlated with its innovation performance, that is, the stronger the enterprise's antirisk ability is, the better its innovation performance is. (2) The difference in the values of the senior management team is negatively correlated with innovation performance. That is, only when the values of the corporate executive team have a certain consistency can the enterprise have better innovation performance. (3) The consistency of the differences in the values of the senior management team can effectively enhance the enterprise's antirisk ability and enhance its innovation performance. Moreover, the lower level of differences in the values of the senior management team has a more significant moderating effect on corporate innovation performance. The research in this paper enriches and expands the existing research in the following aspects.

Firstly, it discusses the impact mechanism of corporate antirisk capability on corporate innovation performance and conducts an empirical test by using data from Chinese listed companies. The empirical results show that corporate antirisk ability has a positive impact on corporate innovation performance, which is consistent with the research results of some domestic scholars [54]. There may be two reasons. One is that strong corporate antirisk capabilities will increase the efficiency of corporate resource utilization, promote the formation of competitive advantages, and enable companies to have a more stable internal and external environment, thereby improving corporate innovation performance. Second, strong corporate antirisk capabilities will encourage the senior management team to favor investment in high-risk projects, actively seek and seize innovation opportunities, and promote the improvement of corporate innovation performance.

Secondly, it focuses on the impact mechanism of the difference of senior management team values on innovation and innovation performance. It is found that the better the consistency of the differences in the values of the corporate senior management team, the more scientific the corporate decision-making is, especially the strategic investment decision, so the corporate strategy is. The choice of direction, strategic 
objectives, and strategic route will be further optimized, enabling enterprises to quickly adapt to the environment of internal and external innovation transformation of the enterprise and ultimately improve the innovation performance of the enterprise. This is not discovered in previous research. This may be because previous studies have used more executive team overconfidence to examine the impact of the executive team on innovation performance [55]; the overconfidence of the executive team is difficult to accurately reflect the differences in the values of the executive team and the level of difference, which makes it difficult to draw accurate research conclusions. This article uses the differences in the values of the senior management team to analyze the mechanism of the differences in the values of the senior management team on innovation performance and expands the relevant research on the impact of the differences in the values of the senior management team on corporate innovation.

Thirdly, China has a profound cultural heritage and an extremely diverse variety, forming a rich and complex regional culture. This article uses regional cultural differences to measure the difference degree of senior management team values and investigates the moderating effect of the differences in the values of the senior management team in the process of the enterprise's antirisk ability affecting the enterprise's innovation performance from a microperspective. The research results show that the better the consistency of the values of the senior management team is, the better the company's ability to resist risks, and the promotion of its corporate innovation performance is also more obvious. This is also the content less involved in previous studies. Previous studies have mainly explored the impact of the differences in the values of the senior management team on the innovation strategy of the company, or they are controlling the environmental factors of different countries and analyzing the impact of the company's antirisk ability on the innovation performance of the company or the difference in the values of the senior management team. The impact of corporate risk-taking cannot clearly reveal the moderating mechanism that is truly caused by the differences in the values of the senior management team or their consistency [56]. Therefore, the existing related research is further improved and enriched.

It can be seen that an important aspect to solve the problem of improving enterprise innovation performance is to effectively improve the antirisk ability of enterprises, and the consistency of values of the senior management team can enhance the enterprise's antirisk ability. Therefore, companies must improve the corporate governance system from the perspectives of board structure and board governance, especially the geographical and cultural differences of corporate executives, improve the selection and incentive mechanism of corporate executive teams, and strengthen the consistency of corporate executive team values. Secondly, it is necessary to further improve my country's market competition mechanism and continue to maintain and enhance the enterprise's strong antirisk ability. Finally, it is necessary to optimize the value consistency structure of the senior management team and further exert the promotion effect of the consistency of the values of the senior management team on the enterprise's antirisk ability.
Of course, this study also has some shortcomings: Firstly, given that China's regional culture is rich and complex, there have been few previous studies on China's regional cultural differences. Currently, only Zhao [57] has measured the different regional cultures of China for the first time. The measurement of executive values is measured by using their regional cultural data, but the current research has not verified the accuracy of their regional cultural measurement. Future research can revise and enrich the measurement indicators of executive values to further examine the impact of differences in executive values on corporate strategy.

Secondly, this article not only focuses on the impact of corporate antirisk capabilities on corporate innovation performance but only uses corporate financial indicators to measure corporate antirisk capabilities. However, corporate antirisk capabilities are diverse and complex. The resistance measured under other types of indicators' risk capability may have a certain impact on enterprise innovation performance. Future research can extend this research indicator to some nonfinancial indicators of enterprises to further test the more objective and comprehensive impact of antirisk ability on enterprise innovation performance.

\section{Data Availability}

The data used to support the findings of this study are included within the article.

\section{Conflicts of Interest}

The authors declare that they have no conflicts of interest.

\section{References}

[1] X. J. Wu, E. P. Yang, and X. Q. Wang, "Review on the application of transaction cost theory in the research of enterprise strategic management," East China Economic Management, vol. 33, no. 6, pp. 155-166, 2019.

[2] L. Zhang, Y. Y. Guo, S. Zhang, and Y. W. Pan, "Research on the path of venture capital supporting innovation of science and technology enterprises from the perspective of risk tolerance," Scientific Management Research, vol. 37, no. 1, pp. 86-89, 2019a.

[3] D. J. He and J. Y. Lv, "Entrepreneur over confidence, risktaking and innovation performance," New Accounting, no. 10, pp. 10-14, 2018.

[4] Y. Zhu and G. Wang, "The impact of technical executive power and non-technical executive power on enterprise performance--an empirical test from China's a-share listed high-tech enterprises," Accounting Research, no. 12, pp. 73-79, 2017.

[5] W. W. Li and Y. Y. Zhang, "The impact of the fault zone of senior management team on enterprise performance: review and prospect," Monthly Journal of Finance and Accounting, no. 23, pp. 113-120, 2018.

[6] W. Liu and G. Xiang, "Enterprise sustainable innovation process: a new perspective from knowledge accumulation to continuous learning," Exploration of Economic Problems, no. 8, pp. 44-47, 2003.

[7] X. L. Wang and Y. Jiang, "Research on Incentive dispersion of senior management team, enterprise risk-taking and strategic performance," Financial Theory and Practice, vol. 40, no. 2, pp. 106-111, 2019. 
[8] C. P. Yu, Y. Shang, and Z. G. Zhang, "The impact of management innovation implementation on innovation performance from the perspective of the integration of structural power and knowledge-based theory," Technical Economy, vol. 38, no. 1, pp. 48-55, 2019.

[9] Y. Meng and J. J. Shi, "Research on the relationship between team social capital and new product development performance--raking team efficacy as an intermediary variable," Journal of Xue-Hai, no. 3, pp. 106-111, 2020.

[10] W. P. Jiang and D. D. Liu, "Research on the relationship between $\mathrm{R} \& \mathrm{D}$ investment, redundant resources and enterprise performance," Financial Theory and Practice, vol. 37, no. 5, pp. 57-62, 2016.

[11] X. C. Xie and F. Shi, "Dynamic response of innovation performance to R \& D investment and its industry differences--PVAR analysis based on panel data of large and medium-sized state-owned enterprises in five industries," Journal of Henan Agricultural University, vol. 17, no. 5, pp. 90-97, 2016.

[12] Z. H. Feng, "Cash holding, corporate governance and agency costs--regulatory effect based on property rights," Economic Management, vol. 39, no. 8, pp. 159-176, 2017.

[13] Z. C. Chen, G. Xiang, B. Ni, and N. Li, "Dynamic analysis of product continuous innovation risk of innovative enterprises based on system dynamics," Scientific and Technological Progress and Countermeasures, vol. 29, no. 19, pp. 82-86, 2012.

[14] Z. J. Zhou, D. Li, and H. R. Wang, "Asset light operation and enterprise risk taking: empirical analysis and impact path," Statistical Research, vol. 37, no. 1, pp. 99-109, 2020.

[15] Y. K. Zhang, S. J. Lai, and X. Q. Du, "Scholar independent directors, product market competition and company innovation investment," Economics and Management, vol. 41, no. 10, pp. 123-142, 2019.

[16] W. N. Huang, D. L. Zhang, and S. H. Li, "Research on the impact of leasing manipulation on enterprise credit risk-from the perspective of IFRS 16-leasing," Macroeconomic research, no. 6, pp. 65-72, 2017.

[17] Y. Z. Sun, S. Chen, and Y. J. Zhang, "Heterogeneity of senior management team, group fault zone and enterprise risk taking," Management Review, vol. 31, no. 8, pp. 157-168, 2019.

[18] W. X. Wang, J. J. Zhang, and Z. Zuo, "Research on the relationship between managers' background characteristics and enterprise credit risk in private enterprises," Friends of $A c$ counting, no. 20, pp. 131-136, 2017.

[19] T. Wang, C. Yu, and B. Xiao, "Risk incentives of foreign direct investment in intellectual property of high-tech enterprises-an empirical study based on China's high-tech enterprises," Research on Science and Technology Management, vol. 39, no. 19, pp. 213-219, 2019.

[20] Q. M. Hao and X. Sun, "Executive characteristics, risk preference and innovation incentive--an empirical test from the data of Chinese listed companies," Modern Finance and Economics (Journal of Tianjin University of Finance and Economics), vol. 35, no. 11, pp. 60-70, 2015.

[21] J. Liu, S. Y. Liang, and X. W. He, "Empirical study on organizational inertia, network location and dual technological innovation--based on the data of manufacturing enterprises in Guangdong Province," Soft Science, vol. 31, no. 7, pp. 24-28, 2017.

[22] P. Bi and P. P. Li, "Environmental regulation, government support and enterprise innovation output," Enterprise economy, vol. 39, no. 6, pp. 70-79, 2020.
[23] H. D. John and S. M. Lundan, "Institutions and the OLI paradigm of the multinational enterprise," Asia Pacific Journal of Management, vol. 25, no. 4, pp. 111-120, 2008.

[24] X. J. Yu and W. J. Xu, "Risk and benefit analysis of various partners of SME credit re guarantee," Systems Engineering, vol. 31, no. 5, pp. 33-39, 2013.

[25] B. L. Li and D. X. He, "Technological frontier, enterprise capability and organizational model," Contemporary Economic Research, no. 12, pp. 53-59, 2012.

[26] Y. S. Zhang, Y. J. Du, and S. Chen, "Research on the incentive effect of patent pool alliance cooperation on technological innovation of high-tech enterprises," Research and Development Management, vol. 31, no. 6, pp. 1-12, 2019.

[27] J. X. Yu and L. Zhou, "Study on Influencing iactors of CEO compensation of small and medium-sized listed energy companies," Financial and Accounting Communication, no. 30, pp. 63-66, 2013.

[28] J. X. He and X. Y. Jing, "Resilient Governance: from public goods vulnerability risk reduction to governance model innovation," Economic and Management Review, vol. 34, no. 1, pp. 68-81, 2018.

[29] X. L. Yao, S. L. Liu, and J. L. Li, "Can CEO equity incentive create value for the shareholders of the acquired company-- based on the dual perspectives of environmental uncertainty and the nature of control rights of major shareholders," Chinese Certified Public Accountants, no. 7, pp. 39-45, 2017.

[30] L. P. Chen, H. L. Zhang, and J. J. Xu, "Property right nature, corporate strategy and corporate risk taking," Financial and Accounting Communication, no. 30, pp. 18-23, 2018.

[31] Z. Y. Xu and Y. Z. Liu, "Private equity investment, board characteristics and corporate performance," Soft Science, vol. 29, no. 10, pp. 69-73, 2015.

[32] D. Q. Jiang, G. Q. Zhang, and J. L. Yu, "Executive network, property right nature and enterprise investment efficiency," Journal of Shanxi University of Finance and Economics, vol. 38, no. 10, pp. 75-88, 2016.

[33] J. Li, W. W. Cao, Y. Qiao, and Z. Pan, "Business expectation gap, risk-taking level and innovation sustainability--a comparative study of private enterprises and non private enterprises," China Soft Science, no. 2, pp. 140-148, 2018.

[34] C. Hong, H. Li, L. L. Zhu, and K. Y. Zhang, "Review and trend prospect of domestic open innovation research," Modern Intelligence, vol. 38, no. 6, pp. 165-171, 2018.

[35] H. F. Sun and X. Y. Wu, "Research progress of enterprise top management team," Journal of Management Science, no. 4, pp. 82-89, 2003.

[36] L. Chen, G. Gao, B. Y. Yang, and R. T. Jing, "Research on the mechanism of paternalistic leadership on the creativity of senior management team members," Journal of Management, vol. 10, no. 6, pp. 831-838, 2013.

[37] W. H. Zhao and M. Zhou, "Research on the impact of human resource management practice of $\mathrm{R} \& \mathrm{D}$ team on enterprise innovation performance," Research and Development Management, vol. 24, no. 4, pp. 61-70, 2012.

[38] B. Q. Xiao and C. H. Shen, "Characteristics of middle management team and enterprise performance in start-up enterprises," Journal of Nanjing Normal University (Social Science Edition), no. 5, pp. 69-79, 2015.

[39] X. Y. Yu, "Research on corporate team culture construction strategy," National Circulation Economy, no. 22, pp. 33-35, 2019.

[40] F. Z. Rong and X. Wang, "Research on the impact of stock option incentive plan on senior executives' strategic decision- 
making risk-taking," Financial and Accounting Communication, no. 35, pp. 38-43, 2018.

[41] G. Chen, "Value conflict and self adjustment of individuals in the team," Comparative Study of Cultural Innovation, vol. 1, no. 22 , pp. 24-26, 2017.

[42] C. C. Wang, H. Liu, and J. Li, "Empirical Study on the impact of organizational identity on employee behavior effectiveness," Science of Science and Technology Management, vol. 31, no. 7, pp. 184-191, 2010.

[43] Q. B. Li, "Chairman characteristics, board independence and corporate innovation performance," Modern Management Science, no. 10, pp. 61-63, 2010.

[44] C. P. Wu and D. Tang, "Enforcement of intellectual property protection, technological innovation and enterprise performance--evidence from Chinese listed companies," Economic Research, vol. 51, no. 11, pp. 125-139, 2016.

[45] M. Liu, T. Yang, and T. J. Zhang, "Research on the promotion mechanism of knowledge team core values recognition on organizational competitiveness--a data test based on Sternberg's perspective of successful intelligence," Research on Science and Technology Management, vol. 35, no. 7, pp. 240-244, 2015.

[46] W. K. Wu, P. P. Fu, and J. Liu, "An Empirical Study on value based leadership behavior and team effectiveness in China," System engineering theory and practice, no. 6, pp. 19-27, 2003.

[47] Y. Zhao and J. Wei, "Research on technical efficiency of China's regional cultural industry--from the perspective of stochastic frontier analysis model," Research on Financial Issues, no. 1, pp. 30-36, 2015.

[48] H. Lin and Y. J. Sun, "Chemical enterprise risk monitoring algorithm based on optimized decision tree," Computer Simulation, vol. 30, no. 8, pp. 368-371, 2013.

[49] H. P. Hu and C. G. Li, "Is the financial performance of channel members really "batch return and zero advance"-_ panel data analysis based on wholesale and retail trade enterprises," Management Review, vol. 24, no. 9, pp. 152-163, 2012.

[50] M. Lu, Y. T. Yang, and X. Y. Qi, "Research on the impact of social responsibility on financial performance of listed companies in Jiangsu," Journal of Southeast University (Social Science Edition), vol. 16, no. S2, pp. 21-25, 2014.

[51] Z. P. Zhang, Y. J. Xia, and D. D. Yang, "Do the dual goals of microfinance institutions conflict with each other--test and comparison based on simultaneous equation model," Agricultural Technology and Economy, no. 4, pp. 16-27, 2016.

[52] Y. Zhou, Y. Zhang, and M. Goh, "Choice of pricing and advertising schemes for a two-sided platform," Managerial and Decision Economics, vol. 42, no. 7, pp. 1865-1885, 2021.

[53] Y. Zhou, Y. Zhang, and M. I. M. Wahab, "Optimal pricing and choice of platform advertising schemes considering acrossside network effect," Managerial and Decision Economics, 2021.

[54] J. Zhang and Z. Z. Huang, "Internal control, technological innovation and corporate performance--an empirical analysis based on listed manufacturing companies in China," Economics and Management, vol. 38, no. 9, pp. 120-134, 2016.

[55] A. He and J. W. Zhong, "R \& D internationalization and enterprise innovation performance--the regulatory role of absorptive capacity and geographical diversity," Southern Economist, no. 10, pp. 92-112, 2018.

[56] M. L. Shan, "Geographical agglomeration and cultural identity: research on the industrialization and sustainable development of regional cultural resources," Shandong Social Sciences, no. 12, pp. 159-164, 2016.
[57] W. P. Zhao, "Contemporary reflection on traditional regional customs,” Academic Exchange, no. 12, pp. 195-199, 2010. 